\title{
Effect of Low-Pass Filtering on Isometric Mid-Thigh Pull Kinetics
}

Original Research

Thomas Dos'Santos ${ }^{1 \#}$, Jason Lake ${ }^{2}$, Paul A Jones ${ }^{1}$ and Paul Comfort ${ }^{1}$

1 Human Performance Laboratory, Directorate of Sport, Exercise, and Physiotherapy,

University of Salford, Greater Manchester, United Kingdom

${ }^{2}$ Department of Sport and Exercise Sciences, University of Chichester, Chichester, United

Kingdom

${ }^{\#}$ Corresponding Author: Thomas Dos'Santos

Telephone: +447961744517

Email: t.dossantos@edu.salford.ac.uk

Brief running head: Filtering and force assessment

Abstract word count: 262 words

Manuscript word count: 3367 words

Number of tables and figures: 2 Tables and 1 Figure 


\section{Abstract}

The purpose of this study was to investigate the effect of low-pass filtering on isometric midthigh pull (IMTP) kinetics, including body weight (BW), onset threshold force, time-specific force values (50, 100, 150 and $200 \mathrm{~ms})$ and peak force (PF). Forty IMTP trials from twentyfour collegiate athletes (age: $21.2 \pm 1.8$ years, height: $1.72 \pm 0.09 \mathrm{~m}$, mass: $79.4 \pm 8.2 \mathrm{~kg}$ ) were analyzed and compared using unfiltered (UF) and low-pass filtered (LPF) (Fourth-order Butterworth) with cut-off frequencies of 10 (LPF10) and 100 (LPF100) Hz. Significantly lower $(p<0.001, g=-0.43$ to- 0.99$)$ onset threshold forces were produced when force data were LPF. This led to significant $(p<0.001, g=0.05-0.21)$ underestimations of time-specific force values when LPF10 compared to UF, displaying unacceptable percentage differences $(1.2-3.3 \%)$ and unacceptable limits of agreement (LOA) (-25.4 to $100.3 \mathrm{~N})$. Although significantly different $(p \leq 0.049)$, trivial $(g \leq 0.04)$ and acceptable percentage differences $(\leq 0.8 \%)$ and acceptable LOA $(-28.0$ to $46.2 \mathrm{~N})$ in time-specific force values were observed between UF and LPF100. Statistically significant $(p<0.001)$, yet trivial $(g \leq 0.03)$, and acceptable percentage differences $(\leq 0.7 \%)$ and acceptable LOA $(-4.7$ to $33.9 \mathrm{~N})$ were demonstrated in PF between filtering conditions. No significant differences $(p=1.000)$ and identical BW values were observed between filtering conditions. Low-pass filtering results in underestimations in IMTP kinetics; however, these differences are acceptable between LPF100 and UF, but unacceptable between LPF10 and UF (excluding PF). Filtering procedures should be standardized when longitudinally monitoring changes in IMTP forcetime characteristics to allow valid comparisons; with analysis of UF data recommended.

Key words: peak force; time-specific force; force-time curve; smoothing; assessment 


\section{INTRODUCTION}

The ability to produce high levels of force is an important quality underpinning athletic performance $(25,30)$, thus methods of assessments available to evaluate the rapid force production capabilities of athletes are of great interest to coaches. One such assessment which permits a comprehensive examination of the rapid force production qualities of athletes is the isometric mid-thigh pull (IMTP) $(1,10,16,18)$. The IMTP is a time efficient and potentially safer mode of assessing maximum strength in comparison to dynamic one-repetition testing (16). A distinct advantage of IMTP testing is the ability to examine force at- $(1,10,16,18)$, rate of force development over- $(1,10,16,18)$, and impulse $(7,31)$ during critical time intervals (50-300 ms) similar to the ground contact and contraction times of sprinting and changing direction $(11,37)$. Furthermore, these IMTP kinetics have been shown to be highly reliable within- $(10,18)$ and between sessions $(7,13,15)$, and are commonly included in the testing batteries of numerous sporting populations such as soccer (15) tennis (17), rugby (8$10,35,36)$, mixed martial arts (21) and weightlifting $(1,3)$.

The IMTP is used to monitor and track changes in performance (16), assess neuromuscular preparedness (17) and evaluate unilateral asymmetries (12). With this information coaches can make informed decisions regarding an athlete's strengths and weaknesses to subsequently inform future prescription of training (26). However, in order to permit accurate, valid and reliable assessments of IMTP force-time characteristics, a robust and standardized testing methodology and appropriate force-time curve (FTC) analysis is required. Substantial variations have been reported in IMTP testing methodologies and analysis procedures. These include: IMTP apparatus, joint angles and body positions relative to the bar, verbal instructions and attentional focus, sampling frequencies $(500-1000 \mathrm{~Hz})$ and onset thresholds, all of which may affect the resultant IMTP kinetics obtained $(3,9,13,14,19,22)$. 
Thus, it is imperative that coaches consider and understand the implications of the abovementioned factors when conducting IMTP testing.

One factor that could potentially compromise the accuracy of IMTP force-time characteristics derived from the FTC is the application of a low-pass filter and cut-off frequency (COF) selection. Filtering may be performed in an attempt to remove noise while preserving as much of the signal as possible (28); however, to date, there are no recommendations on whether to filter IMTP force-data, as a diverse range of filtering procedures have been adopted and reported within the literature. For example, fourth-order Butterworth low-pass filters are commonly adopted, but variations in the COFs have been reported and include 100 $\mathrm{Hz}(1,2), 20 \mathrm{~Hz}(8,27,36), 16 \mathrm{~Hz}(31-33)$ and $10 \mathrm{~Hz}(21,22)$. Additionally, previous investigations have analysed the FTCs using rectangular smoothing with a moving half-width of $12(18,24)$. Conversely, some researchers have analyzed unfiltered FTC data $(13-15,23)$, whereas previous studies have failed to state whether filtered or unfiltered data were analyzed $(7,9,17,35)$, thus making it difficult to facilitate methodological replication. Street et al. (29) recommended analysis of unfiltered force-time data for the calculation of jump height during countermovement jumping and reported underestimations in jump height of 26 and $31 \%$ using low-pass (second-order Butterworth filter) filters with COFs of 6 and $14 \mathrm{~Hz}$, respectively. However, the effect of low-pass filtering on IMTP kinetics has yet to be investigated.

There is a requirement therefore, for an investigation into the effects of low-pass filtering on IMTP kinetics, as it is unknown whether different filtering procedures will affect resultant values for IMTP kinetics. Coaches use the IMTP to assess the maximal and rapid force production capacities of athletes and typically compare values to normative data published in the literature. The results from this study should improve our understanding of whether to filter force-time data, and may also advise caution when comparing IMTP kinetics to studies 
that have adopted different filtering conditions. Thus, the aim of this study was to compare IMTP body weight (BW), onset threshold forces, contraction start time identification, timespecific force values (50, 100, 150 and $200 \mathrm{~ms})$ and PF between unfiltered (UF) and low-pass filtered (LPF) (Fourth-order Butterworth) force-time data. COFs of 10 (LPF10) and 100 (LPF100) $\mathrm{Hz}$ were investigated as these COFs have been commonly reported within the literature $(1-3,21,22)$. It was hypothesized that the highest IMTP kinetics would be demonstrated with UF force-time data and low-pass filtered $10 \mathrm{~Hz}$ would produce the lowest IMTP kinetics. It was further hypothesized that significantly greater onset threshold forces would be observed with unfiltered force-time data and no significant differences in BW would be observed between filtering conditions.

\section{METHODS}

Experimental approach to the problem

A retrospective analysis of forty IMTP trials from previously published data (13) which demonstrated excellent between-session reliability measures (Intraclass correlation coefficients $=0.84-0.97$, coefficient of variation $=4.5-8.0 \%$, standard error of measurement $=$ 109.5-121.4 N) was performed. An a priori power analysis using $\mathrm{G}^{*}$ Power (Version 3.1, University of Dusseldorf, Germany) (16) confirmed a minimum sample size of 27 trials was required to detect a medium effect size (0.50), a power of 0.80 and type 1 error or alpha level of 0.05 . A repeated-measures, within-subjects design was used to determine the effect of lowpass filtering and COF on BW (weighing period force), onset threshold force, contraction start time identification, force at 50-, 100-, 150-, $200 \mathrm{~ms}$ and PF. Subjects performed maximum effort IMTPs while standing on a force plate sampling at $1000 \mathrm{~Hz}$. Force-time data were treated in three different ways. 
They were either left unfiltered (UF), low-pass filtered with a COF of $10 \mathrm{~Hz}$, or low-pass filtered with a COF of $100 \mathrm{~Hz}$ and analyzed using a customized analysis spreadsheet. The IMTP kinetic values were compared across filtering conditions (UF, LPF10 and LPF100) to explore any differences in values.

Subjects

Twenty-four collegiate athletes from rowing and soccer (age: $21.2 \pm 1.8$ years, height: $1.72 \pm$ $0.09 \mathrm{~m}$, mass: $79.4 \pm 8.2 \mathrm{~kg}$ ) took part in this study, and were informed of the benefits and risks of the investigation before providing informed consent to participate in this study. This study was approved by the university institution review board. Subjects were familiar with the IMTP protocol and had $\geq 6$ months resistance training experience of the power clean and its' derivatives. At the time of testing subjects were mid-season in the first week of a power mesocycle having performed a four-week maximum strength mesocycle. All testing took place between 17:00-19:00 which coincided with normal resistance training sessions, and subjects were required to abstain from training for 48 hours before testing and asked to maintain a consistent fluid and dietary intake on each day of testing.

Procedures

Pre-isometric assessment warm up

All subjects performed a standardized warm up comprised of ten body weight squats and lunges followed by two IMTP efforts at a perceived intensity of 50, and $75 \%$ of maximum effort, interspersed with a one-minute rest period (2). 
Isometric mid-thigh pull protocol

The IMTP testing was performed on a portable force plate sampling at $1000 \mathrm{~Hz}$ (10) (type: 9286AA, dimensions 600 mm x 400 mm, Kistler Instruments Inc., Amherst, NY, USA) using a portable IMTP rack (Fitness Technology, Adelaide, Australia). A cold rolled steel bar was positioned to correspond to the athlete's second-pull power clean position just below the crease of the hip (1). The bar height could be adjusted $(3 \mathrm{~cm}$ increments $)$ at various heights above the force plate to accommodate different sized athletes. Athletes were strapped to the bar in accordance to previous research (12) and positioned in knee and hip joint angles of $145^{\circ}(13)$ established in the familiarization trials, whereby feet were shoulder width apart and under the bar, knees were flexed over the toes, shoulders were just behind the bar, and torso was upright $(10,12)$. All subjects received standardized instructions to pull as "fast and as hard as possible and push their feet directly into the force plate" until being told to stop, as these instructions have been shown to provide optimal results $(4,19)$. Once the body was stabilized (verified by watching the subject and force trace) the IMTP was initiated with the countdown " 3,2 , 1, pull," with subjects ensuring that maximal effort was applied for five seconds. Ground reaction force data were collected for eight seconds from the portable force platform which was interfaced with a laptop running Bioware software (Version 5.11; Kistler Instrument Corporation, Amherst, NY, USA). Minimal pre-tension was allowed to ensure there was no slack in the body prior to pull initiation and subjects were instructed to be as still as possible during the weighing period, without initiating a pull on the bar, until given the instructions to 'pull'. Strong verbal encouragement was given for all trials. Trials without a stable baseline force trace during the weighing period (change in force $>50 \mathrm{~N}$ ) were rejected along with trials with a countermovement (decrease in body weight $>50 \mathrm{~N})(14,25)$; subsequently, another trial was performed. 
Isometric Force-Time-Curve Assessment

Raw force-time data were filtered with a fourth-order Butterworth low-pass filter using COF of 10 and $100 \mathrm{~Hz}$. These COFs were based on their application in previous research $(1-3,21$, 22). Therefore, three filtering conditions were examined to determine the influence of LPF and COF on IMTP kinetics. These were UF, LPF10 and LP100 force-time data. Low-pass filtering was performed using an add-in for Microsoft Excel that is available online (34). The filtered and unfiltered IMTP force-time data were inspected using a customized Microsoft Excel spreadsheet (version 2016, Microsoft Corp., Redmond, WA, USA) to determine specific force-time characteristics. The maximum force generated during the five second maximum effort IMTP was reported as the absolute PF (18). Additionally, time-specific force values of force at $50 \mathrm{~ms}\left(\right.$ Force $\left._{50}\right), 100 \mathrm{~ms}$ (Foree 100$), 150 \mathrm{~ms}\left(\right.$ Force $\left._{150}\right)$ and $200 \mathrm{~ms}$ (Force 200 ) were calculated (18). The onset of the pull was determined when vertical groundreaction force deviated $5 \mathrm{SD}$ (defined as onset threshold force) from the average body weight during the weighing period (14). The BW (5 SD) were calculated as the average force over a one second stationary weighing period (in mid-thigh pull position posture) prior to IMTP initiation (14). The force plate was zeroed between each trial when participants stood off the force plate, thus all force-time variables included body weight.

Statistical Analyses

Statistical analyses were performed using SPSS software version 23 (SPSS, Chicago, Ill, USA) and Microsoft Excel. Normality for all variables was inspected using a Shapiro Wilkstest and revealed all variables were parametric excluding PF and onset threshold force, respectively. IMTP kinetics were compared across the three filtering conditions using a repeated measures ANOVA (RMANOVA) with Bonferroni post-hoc pairwise comparisons in cases of significant differences for parametric variables. 
For non-parametric variables a Friedman's test was used and in cases of significant differences individual Wilcoxon sign ranked tests were used. Standardized differences were calculated using Hedges' $g$ effect sizes as described previously (20) and interpreted using Cohen's scale (6). The mean of the difference (bias) was calculated and percentage differences were also calculated using the formula: (UF-LPF)/UF x 100 or (LPF100LPF10)/LPF100 x 100. The 95\% limits of agreement (LOA) (LOA: mean of the difference \pm 1.96 standard deviations) were calculated between filtering conditions using methods described by Bland and Altman (5). Percentage differences $\leq 1 \%$ were considered acceptable (29). Statistical significance was defined $p \leq 0.05$ for all tests.

\section{RESULTS}

Mean \pm SD are presented for all IMTP kinetics across filtering conditions in Table 1. RMANOVA revealed filtering had no significant effect on BW with identical values produced between conditions (Tables 1-2). RMANOVA revealed filtering had no significant effect on contraction start time identification (Table 1). Friedman's test revealed filtering condition had a significant effect on onset threshold force (Table 1). Pairwise comparisons revealed that significantly higher onset threshold forces were produced during UF conditions (Table 2). These differences were classed as moderate to large, and they displayed unacceptable percentage differences (17.2-32.7\%) and unacceptable LOA (2.9-12.5 N) (Table 2).

RMANOVA revealed that filtering had a significant effect on time-specific force values (Table 1). Pairwise comparisons revealed that significantly higher time-specific force values were produced during UF conditions compared to LPF10. (Table 2). These differences were classed as trivial to small, and they displayed small bias (21.6-47.6 N), unacceptable 
percentage differences (1.2-3.3\%) and unacceptable LOA (-25.4 to $100.3 \mathrm{~N}$ ) (Table 2). Pairwise comparisons revealed that significantly higher time-specific force values were produced during UF conditions compared to LPF100 (Table 2). However, these differences were classed as minimal and trivial, and they displayed low bias (6.7-12 N), acceptable percentage differences $(\leq 0.8 \%)$ and acceptable LOA $(-28.0$ to $46.2 \mathrm{~N})$ (Table 2). Significantly higher time-specific force values were produced during LP100 compared to LPF10 (Table 2). These differences were classed as trivial, and they displayed small bias (13.6-30.1 N); however, acceptable percentage differences for Force 200 (0.7\%), whereas unacceptable percentage differences were revealed for the other time-specific force values $(1.5-2.7 \%)$ (Table 2). Friedman's test revealed filtering had a significant effect on PF (Table 1). Pairwise comparisons revealed that significantly higher PF values were produced during UF conditions (Table 2). However, these differences were classed as minimal and trivial, and they displayed low bias (3.3-12.9 N), acceptable percentage differences $(\leq 0.7 \%)$ and acceptable LOA (-4.7 to $33.9 \mathrm{~N}$ ) (Table 2).

\section{***Insert Table 1 about here***}

***Insert Table 2 about here***

\section{DISCUSSION}

To our knowledge, this is the first study to examine the effect of low-pass filtering on IMTP kinetics. The primary findings were underestimations in PF and time-specific force values were produced when low-pass filtering force-time data in comparison to UF (Table 1-2); supporting the study hypothesis. However, it is worth noting that acceptable percentage differences and acceptable LOA were observed between UF and LP100 for all IMTP kinetics (Table 2). Conversely, unacceptable percentage differences and unacceptable LOA in timespecific force values were demonstrated between UF and LPF10 (Table 2). 
Additionally, when the lower COF is used notably lower onset threshold forces are produced compared to UF conditions (Table 2). However, filtering had no impact on BW with identical values produced for all conditions (Table 2).

The present study confirmed filtering has a statistically significant effect on IMTP kinetics, revealing different values were obtained when a low-pass filter with different COFs was applied (Tables 1-2). These findings corroborate the results of Street et al. (29) who showed differences in jump height and net impulse with the application of different LPF COFs. The application of a LPF100 in comparison to UF had a statistically significant, though trivial and minimal effect on IMTP kinetics, displaying low bias (6.7-12 N), and acceptable percentage differences $(\leq 0.8 \%)$ and acceptable LOA (Table 2). Interestingly, comparisons between UF and LPF10 revealed PF was the only variable to achieve acceptable percentage difference criteria $(0.7 \%)$ (Table 2). Conversely, greater bias (21.6-47.6 N), and unacceptable percentage differences (1.2-3.3\%) and unacceptable LOA were observed between LPF10 and UF conditions for time-specific force values (Table 2), indicating a stronger agreement in IMTP time-specific force values between UF and LPF100. These findings suggest that the IMTP force-time data should not, therefore, be low-pass filtered as underestimations in PF and time-specific values are obtained.

The lower time-specific force values observed during the filtered conditions can be partially attributed to the lower onset threshold forces which subsequently resulted in an earlier onset of contraction time (Tables $1 \& 2$ ) as illustrated in Figure 1. Low-pass filtering resulted in lower onset threshold forces by reducing the noise associated during the weighing period calculation. This in turn, resulted in an onset of contraction start time identification on average 0.002-0.006 seconds earlier during LPF100 and LPF10 conditions, in contrast to UF force-time data (Table 2). Thus, the earlier onset of contraction time resulted in the identification of time-specific force values during a lower portion of FTC, leading to slightly 
lower time-specific force values during filtered conditions and the subsequent curve values would be less because of low-pass filtering (Figure 1).

****Insert Figure 1 about here***

The results of this study confirm different IMTP force-time values are produced when LPF (Tables 1-2). Specifically, LPF10 results in significant and unacceptable underestimations of IMTP kinetics in comparison to UF (Table 2). LPF100 resulted in acceptable percentage differences in comparison to UF; however, it should be noted that these values were still marginally lower, thus, underestimated IMTP kinetics. Previous research has applied a $\operatorname{LPF} 10(1,2)$ and $\operatorname{LP} 100(1,2)$ when analyzing their force-time data, thus rationalising the selection of these low-pass filters and COFs in the present study. But while this is the case it may be useful to expand on the present study to explore the effect of other filtering strategies such as rectangular smoothing with a moving half-width of $12(18,24)$ or low-pass filtering with COF of $16(31-33)$ and $20 \mathrm{~Hz}(8,27,36)$ respectively.

Nonetheless, within context of these limitations, this study found different IMTP kinetic values are produced when different filtering conditions are applied to IMTP force-time data. Therefore, coaches should take into consideration the filtering conditions when interpreting and comparing published normative IMTP data. In addition, when publishing research findings related to IMTP testing, researchers should analyze UF data or clearly state their filtering procedures if using automated software that automatically applies a low-pass filter or their rationale for applying a digital filter. Based on the results of this study, UF data should be analyzed, but if coaches have started monitoring performance across a season using a filtering procedure, they should not change this when monitoring longitudinally across the rest of the season to ensure that the resultant variables are comparable, and not impacted by the change in procedures. 
Correct IMTP administration and analysis of the FTC is essential for obtaining accurate, valid and reliable assessments of an athlete's neuromuscular qualities. Previous studies have shown that the testing apparatus can affect IMTP PF production by $~ 12.4 \%$ (22) and $~ 9.5 \%$ (9), and that hip joint angle can influence PF and time-specific force production with small to large effect sizes $(3,13)$ and percentage differences of 2.6-21.1\% observed for IMTP kinetics (13). Additionally, attentional focus can also impact PF values by $\sim 9.0 \%$ (19), while administration of inappropriate onset thresholds can lead to inflated time-specific force values of $2.0-6.0 \%$ (14). The present study observed mean percentage differences of $\leq 0.7 \%$ and $\leq 3.3 \%$ for PF and time-specific force values between filtering conditions (Table 2). These differences are lower than the abovementioned factors, indicating testing apparatus, joint angle, attentional focus and onset thresholds appear to have a greater effect on IMTP kinetics in comparison to filtering conditions. Nonetheless, low-pass filtering does influence IMTP kinetics, producing subtle differences in values. Therefore, researchers and coaches are recommended to standardize filtering conditions, in addition to standardizing onset threshold (14), attentional focus (19), IMTP testing apparatus $(9,22)$ and joint angles $(3,13)$ when longitudinally monitoring changes in athletes IMTP kinetics to allow valid comparisons. Failure to standardize these abovementioned factors may lead to inaccurate and different evaluations of an athlete's rapid force production capabilities.

\section{PRACTICAL APPLICATIONS}

The results of this study reveal that slightly different values are produced when UF and LPF IMTP force-time data are compared, with LPF data tending to reduce force values. As such, these findings indicate that different filtering conditions should not be used interchangeably when longitudinally monitoring changes in IMTP force-time characteristics. 
Researchers and coaches are therefore advised to standardize filtering procedures (i.e. UF or same type of filter and $\mathrm{COF}$ ) when longitudinally monitoring changes in athlete's isometric force-time characteristics. Such standardization will provide greater certainty and validity that changes in performance can be attributed to adaptation or fatigue, and are caused by inconsistent filtering procedures. Researchers and coaches starting with IMTP testing should not apply a low-pass filter to their force-time data, in particular with a COF selection of 10 $\mathrm{Hz}$ due to the underestimations in time-specific force values. Additionally, coaches should consider the filtering procedures adopted by previous studies when comparing their data to published normative data, as underestimations in $\mathrm{PF}(\leq 0.8 \%)$ and time specific-force values $(\leq 3.3 \%)$ are obtained when IMTP force-time data is LPF. Furthermore, researchers are recommended that when publishing research, they clearly report their filtering procedures (i.e. UF, type of filter and COF) due to the slight effect on IMTP kinetics, and to facilitate methodological replication.

\section{ACKNOWLEDGEMENTS}

The authors would like to thank the athletes for their participation. No funding was received in support of this study and the authors have no conflict of interest.

The findings of this investigation do not represent the views of the NSCA and do not constitute endorsement of any equipment used, by the authors, or the NSCA.

\section{REFERENCES}

1. Beckham G, Mizuguchi S, Carter C, Sato K, Ramsey M, Lamont H, Hornsby G, Haff G, and Stone M. Relationships of isometric mid-thigh pull variables to weightlifting performance. J Sports Med Phys Fitness 53: 573-581, 2013.

2. Beckham G, S. Lamont H, Sato K, W. Ramsey M, and H. Stone M. Isometric strength of powerlifters in key positions of the conventional deadlift. Journal of Trainology 1: 32-35, 2012. 
3. Beckham GK, Sato K, Mizuguchi S, Haff GG, and Stone MH. Effect of Body Position on Force Production During the Isometric Mid-Thigh Pull. The Journal of Strength \& Conditioning Research: Published Ahead of Print, 2017.

4. Bemben MG, Clasey JL, and Massey BH. The effect of the rate of muscle contraction on the force-time curve parameters of male and female subjects. Research quarterly for exercise and sport 61: 96-99, 1990.

5. Bland JM and Altman D. Statistical methods for assessing agreement between two methods of clinical measurement. The lancet 327: 307-310, 1986.

6. $\quad$ Cohen J. Statistical analysis for the behavioral sciences. Hillsdale: Lawrance Erlbaum, 1988.

7. Comfort P, Jones PA, McMahon JJ, and Newton R. Effect of Knee and Trunk Angle on Kinetic Variables During the Isometric Mid-Thigh Pull: Test-Retest Reliability. Int I Sports Physiol and Perform 10: 58-63, 2015.

8. Crewther B, Kilduff L, Cook CJ, Cunningham D, Bunce P, Bracken R, and Gaviglio C. Relationships between salivary free testosterone and the expression of force and power in elite athletes. The Journal of sports medicine and physical fitness 52: 221-227, 2012.

9. Dobbin N, Hunwicks R, Jones B, Till K, Highton J, and Twist C. Criterion and Construct Validity of an Isometric Mid-Thigh Pull Dynamometer for Assessing Whole Body Strength in Professional Rugby League Players. International Journal of Sports Physiology and Performance: Published Ahead of Print, 2017.

10. Dos' Santos T, Jones PA, Kelly J, McMahon JJ, Comfort P, and Thomas C. Effect of Sampling Frequency on Isometric Mid-Thigh Pull Kinetics. Int J Sports Physiol and Perform 11: 255-260, 2016.

11. Dos'Santos T, Thomas C, Jones AP, and Comfort P. Mechanical determinants of faster change of direction speed performance in male athletes. The Journal of Strength \& Conditioning Research 31: 696-705, 2017.

12. Dos'Santos $T$, Thomas $C$, Jones PA, and Comfort P. Assessing muscle strength asymmetry via a unilateral stance isometric mid-thigh pull. International journal of sports physiology and performance 12: 505-511, 2017.

13. Dos'Santos T, Thomas C, Jones PA, McMahon JJ, and Comfort P. The Effect Of Hip Joint Angle On Isometric Mid-Thigh Pull Kinetics. The Journal of Strength \& Conditioning Research:

Published Ahead of Print, 2017.

14. Dos'Santos T, Jones PA, Comfort P, and Thomas C. Effect of Different Onset Thresholds on Isometric Mid-Thigh Pull Force-Time Variables. The Journal of Strength \& Conditioning Research: Published Ahead of Print, 2017.

15. Dos'Santos T, Thomas C, Comfort P, McMahon JJ, Jones PA, Oakley NP, and Young AL. Between-Session Reliability Of Isometric Mid-Thigh Pull Kinetics And Maximal Power Clean Performance In Male Youth Soccer Players. The Journal of Strength \& Conditioning Research: Published Ahead of Print, 2017.

16. Drake D, Kennedy R, and Wallace E. The Validity and Responsiveness of Isometric Lower Body Multi-Joint Tests of Muscular Strength: a Systematic Review. Sports Medicine-Open 3: 23, 2017.

17. Gescheit DT, Cormack SJ, Reid M, and Duffield R. Consecutive Days of Prolonged Tennis Match Play: Performance, Physical, and Perceptual Responses in Trained Players. International Journal of Sports Physiology \& Performance 10, 2015.

18. Haff GG, Ruben RP, Lider J, Twine C, and Cormie P. A comparison of methods for determining the rate of force development during isometric midthigh clean pulls. The Journal of Strength \& Conditioning Research 29: 386-395, 2015.

19. Halperin I, Williams KJ, Martin DT, and Chapman DW. The effects of attentional focusing instructions on force production during the isometric midthigh pull. The Journal of Strength \& Conditioning Research 30: 919-923, 2016.

20. Hedges L and Olkin I. Statistical Methods for Meta-Analysis. New York: Acdemic Press, 1985. 
21. James LP, Beckman EM, Kelly VG, and Haff GG. The Neuromuscular Qualities of Higher and Lower-Level Mixed Martial Arts Competitors. International journal of sports physiology and performance: Published Ahead of Print, 2016.

22. James LP, Roberts LA, Haff GG, Kelly VG, and Beckman EM. The validity and reliability of a portable isometric mid-thigh clean pull. J Strength Cond Res 31: 1378-1386, 2017.

23. Khamoui AV, Brown LE, Nguyen D, Uribe BP, Coburn JW, Noffal GJ, and Tran T. Relationship between force-time and velocity-time characteristics of dynamic and isometric muscle actions. J Strength Cond Res 25: 198-204, 2011.

24. Leary BK, Statler J, Hopkins B, Fitzwater R, Kesling T, Lyon J, Phillips B, Bryner RW, Cormie P, and Haff GG. The relationship between isometric force-time curve characteristics and club head speed in recreational golfers. J Strength Cond Res 26: 2685-2697, 2012.

25. Maffiuletti NA, Aagaard P, Blazevich AJ, Folland J, Tillin N, and Duchateau J. Rate of force development: physiological and methodological considerations. European journal of applied physiology 116: 1091-1116, 2016.

26. McGuigan MR, Cormack SJ, and Gill ND. Strength and Power Profiling of Athletes: Selecting Tests and How to Use the Information for Program Design. Strength \& Conditioning Journal 35: 7-14, 2013.

27. Oranchuk DJ, Robinson TL, Switaj ZJ, and Drinkwater EJ. Comparison of the Hang High-Pull and Loaded Jump Squat for the Development of Vertical Jump and Isometric Force-Time Characteristics. The Journal of Strength \& Conditioning Research: Published Ahead of Print, 2017.

28. Robertson G, Caldwell G, Hamill J, Kamen G, and Whittlesey S. Research methods in biomechanics, 2E. Human Kinetics, 2013.

29. Street G, McMillan S, Board W, Rasmussen M, and Heneghan JM. Sources of error in determining countermovement jump height with the impulse method. Journal of Applied Biomechanics 17: 43-54, 2001.

30. Suchomel TJ, Nimphius S, and Stone MH. The Importance of Muscular Strength in Athletic Performance. Sports Medicine 46: 1419-1449, 2016.

31. Thomas C, Comfort $\mathrm{P}, \mathrm{Chiang} \mathrm{C}-\mathrm{Y}$, and Jones $\mathrm{P}$. Relationship between isometric mid-thigh pull variables and sprint and change of direction performance in collegiate athletes. Journal of Trainology 4: 6-10, 2015.

32. Thomas C, Jones PA, and Comfort P. Reliability of the Dynamic Strength Index in Collegiate Athletes. Int J Sports Physiol and Perform 10: 542 -545, 2015.

33. Thomas $\mathrm{C}$, Jones PA, Rothwell J, Chiang CY, and Comfort P. An Investigation into the Relationship between Maximum Isometric Strength and Vertical Jump Performance. J Strength Cond Res 29: 2176-2185, 2015.

34. Vanrenterghem J. Biomechanics Toolbar. 2016. http://www.biomechanicstoolbar.org/. Accessed 1st September/2017.

35. Wang R, Hoffman JR, Tanigawa S, Miramonti AA, La Monica MB, Beyer KS, Church DD, Fukuda DH, and Stout JR. Isometric Mid-Thigh Pull Correlates With Strength, Sprint, and Agility Performance in Collegiate Rugby Union Players. The Journal of Strength \& Conditioning Research 30: 3051-3056, 2016.

36. West DJ, Owen NJ, Jones MR, Bracken RM, Cook CJ, Cunningham DJ, Shearer DA, Finn CV, Newton RU, and Crewther BT. Relationships between force time characteristics of the isometric midthigh pull and dynamic performance in professional rugby league players. $J$ Strength Cond Res 25: 3070-3075, 2011.

37. Weyand PG, Sternlight DB, Bellizzi MJ, and Wright S. Faster top running speeds are achieved with greater ground forces not more rapid leg movements. Journal of applied physiology 89: 1991-1999, 2000. 
Table 1 - Descriptive statistics for IMTP kinetics across filtering conditions

\begin{tabular}{|c|c|c|c|c|c|c|c|}
\hline \multirow[t]{2}{*}{ IMTP variable } & \multicolumn{2}{|c|}{ UF } & \multicolumn{2}{|c|}{ LPF10 } & \multicolumn{2}{|c|}{ LPF100 } & \multirow{2}{*}{$\begin{array}{c}\text { RMANOVA/Friedman's } \\
p \text { value }\end{array}$} \\
\hline & Mean & SD & Mean & SD & Mean & SD & \\
\hline $\mathrm{PF}(\mathrm{N})$ & 2627 & 531 & 2611 & 533 & 2623 & 532 & $<0.001$ \\
\hline Force $_{50}(\mathrm{~N})$ & 1078 & 178 & 1042 & 167 & 1072 & 178 & $<0.001$ \\
\hline Force $_{100}(\mathrm{~N})$ & 1376 & 256 & 1344 & 247 & 1365 & 256 & 0.001 \\
\hline Force $_{150}(\mathrm{~N})$ & 1763 & 402 & 1715 & 388 & 1751 & 406 & 0.004 \\
\hline Force $_{200}(\mathrm{~N})$ & 1993 & 418 & 1972 & 423 & 1985 & 422 & 0.009 \\
\hline $\mathrm{BW}(\mathrm{N})$ & 819.2 & 148.3 & 819.2 & 148.3 & 819.2 & 148.3 & 0.627 \\
\hline Onset threshold force $(\mathrm{N})$ & 25.9 & 6.8 & 18.2 & 8.5 & 21.6 & 72 & $<0.001$ \\
\hline Contraction start time (s) & 1.952 & 0.289 & 1.946 & 0.290 & 1.950 & 0.289 & 0.425 \\
\hline
\end{tabular}

Key: IMTP: Isometric mid-thigh pull; LPF10: Low-pass filtered; with a cut-off frequency of $10 \mathrm{~Hz}$; LPF100: Low-pass filtered; with a cut-off frequency of $100 \mathrm{~Hz}$; UF: Unfiltered; Force ${ }_{50}$ : Force at $50 \mathrm{~ms}$; Force 100 : Force at $100 \mathrm{~ms}$; Force 150 : Force at $150 \mathrm{~ms}$; Force 200 : Force at $200 \mathrm{~ms}$; BW: Body weight; (Bold denotes non-parametric) 


\begin{tabular}{|c|c|c|c|c|c|c|c|c|}
\hline \multicolumn{9}{|c|}{ UF vs LPF10 } \\
\hline \multirow{2}{*}{ IMTP variable } & \multirow{2}{*}{$p$} & \multirow{2}{*}{$g$} & \multirow{2}{*}{ Bias } & \multirow{2}{*}{$S D$} & \multicolumn{2}{|c|}{$\%$ difference } & \multicolumn{2}{|c|}{$95 \% \mathrm{LOA}$} \\
\hline & & & & & Mean & SD & LB & UB \\
\hline $\mathrm{PF}(\mathrm{N})$ & $<0.001$ & 0.03 & 16.1 & 9.1 & 0.7 & 0.5 & -1.6 & 33.9 \\
\hline Force $_{50}(\mathrm{~N})$ & $<0.001$ & 0.21 & 36.8 & 23.9 & 3.3 & 2.0 & -10.0 & 83.6 \\
\hline Force $_{100}(\mathrm{~N})$ & $<0.001$ & 0.13 & 31.9 & 28.9 & 2.3 & 2.0 & -24.7 & 88.5 \\
\hline Force $_{150}(\mathrm{~N})$ & $<0.001$ & 0.12 & 47.6 & 26.9 & 2.7 & 1.4 & -5.0 & 100.3 \\
\hline Force $_{200}(\mathrm{~N})$ & $<0.001$ & 0.05 & 21.6 & 24.0 & 1.2 & 1.3 & -25.4 & 68.6 \\
\hline $\mathrm{BW}(\mathrm{N})$ & 1.000 & 0.00 & -0.001 & 0.047 & 0.000 & 0.006 & -0.092 & 0.090 \\
\hline Onset threshold force $(\mathrm{N})$ & $<0.001$ & 0.99 & 7.7 & 2.4 & 32.7 & 14.7 & 2.9 & 12.5 \\
\hline Contraction start time (s) & 1.000 & 0.02 & 0.006 & 0.003 & 0.333 & 0.188 & 0.000 & 0.013 \\
\hline \multicolumn{9}{|c|}{ UF vs LPF100 } \\
\hline IMTP variable & $p$ & $g$ & Bias & $S D$ & $\begin{array}{l}\% \mathrm{~d} \\
\text { Mean }\end{array}$ & $\begin{array}{l}\mathrm{ce} \\
\mathrm{SD}\end{array}$ & LD & $\begin{array}{l}\text { A } \\
\text { UB }\end{array}$ \\
\hline $\mathrm{PF}(\mathrm{N})$ & $<0.001$ & 0.01 & 3.3 & 1.3 & 0.1 & 0.1 & 0.7 & 5.9 \\
\hline Force $_{50}(\mathrm{~N})$ & $<0.001$ & 0.04 & 6.7 & 9.2 & 0.6 & 0.5 & -11.3 & 24.7 \\
\hline Force $_{100}(\mathrm{~N})$ & 0.004 & 0.04 & 10.3 & 17.2 & 0.8 & & -23.3 & 43.9 \\
\hline Force $_{150}(\mathrm{~N})$ & 0.001 & 0.03 & 12.0 & 17.5 & & 1.2 & -22.2 & 46.2 \\
\hline Force $_{200}(\mathrm{~N})$ & 0.049 & 0.02 & 8.0 & 18.4 & 0.4 & 1.0 & -28.0 & 44.1 \\
\hline $\mathrm{BW}(\mathrm{N})$ & 1.000 & 0.000 & 0.001 & 0.004 & 0.000 & 0.001 & -0.007 & 0.008 \\
\hline Onset threshold force $(\mathrm{N})$ & $<0.001$ & 0.58 & 4.2 & 1.5 & 17.8 & 9.1 & 1.3 & 7.2 \\
\hline Contraction start time (s) & 1.000 & 0.007 & 0.002 & 0.003 & 0.103 & 0.146 & -0.003 & 0.007 \\
\hline \multicolumn{9}{|c|}{ LPF100 vs LPF10 } \\
\hline \multirow{2}{*}{ IMTP variable } & \multirow{2}{*}{$p$} & \multirow{2}{*}{$g$} & & $D$ & \multicolumn{2}{|c|}{$\%$ difference } & \multicolumn{2}{|c|}{$95 \%$ LOA } \\
\hline & & & & & Mean & SD & LB & UB \\
\hline $\mathrm{PF}(\mathrm{N})$ & $<0.001$ & 0.02 & 12.9 & 9.0 & 0.5 & 0.5 & -4.7 & 30.5 \\
\hline Force $_{50}(\mathrm{~N})$ & $<0.001$ & 0.17 & 30.1 & 23.5 & 2.7 & 2.0 & -16.0 & 76.1 \\
\hline Force $_{100}(\mathrm{~N})$ & $<0.001$ & 0.08 & 21.6 & 23.1 & 1.5 & 1.6 & -23.7 & 66.9 \\
\hline Force $_{150}(\mathrm{~N})$ & $<0.001$ & 0.09 & 35.7 & 28.0 & 1.9 & 1.4 & -19.3 & 90.6 \\
\hline Force $_{200}(\mathrm{~N})$ & $<0.001$ & 0.03 & 13.6 & 16.1 & 0.7 & 0.9 & -18.1 & 45.2 \\
\hline $\mathrm{BW}(\mathrm{N})$ & 1.000 & 0.000 & -0.001 & 0.044 & 0.000 & 0.005 & -0.088 & 0.086 \\
\hline Onset threshold force $(\mathrm{N})$ & $<0.001$ & 0.43 & 3.5 & 2.3 & 18.3 & 13.5 & -1.1 & 8.0 \\
\hline Contraction start time (s) & 1.000 & 0.015 & 0.004 & 0.003 & 0.231 & 0.171 & -0.002 & 0.010 \\
\hline
\end{tabular}

Key: IMTP: Isometric mid-thigh pull; LPF10: Low-pass filtered; with a cut-off frequency of $10 \mathrm{~Hz}$; LPF100: Low-pass filtered; with a cut-off frequency of $100 \mathrm{~Hz}$; UF: Unfiltered; Force ${ }_{50}$ : Force at $50 \mathrm{~ms}$; Force Fo $_{100}$ Force at $100 \mathrm{~ms}$; Force 150 : Force at $150 \mathrm{~ms}$; Force 200 . Force at $200 \mathrm{~ms}$; BW: Body weight; LOA: Limits of agreement; LB: Lower bound; UB: Upper bound 


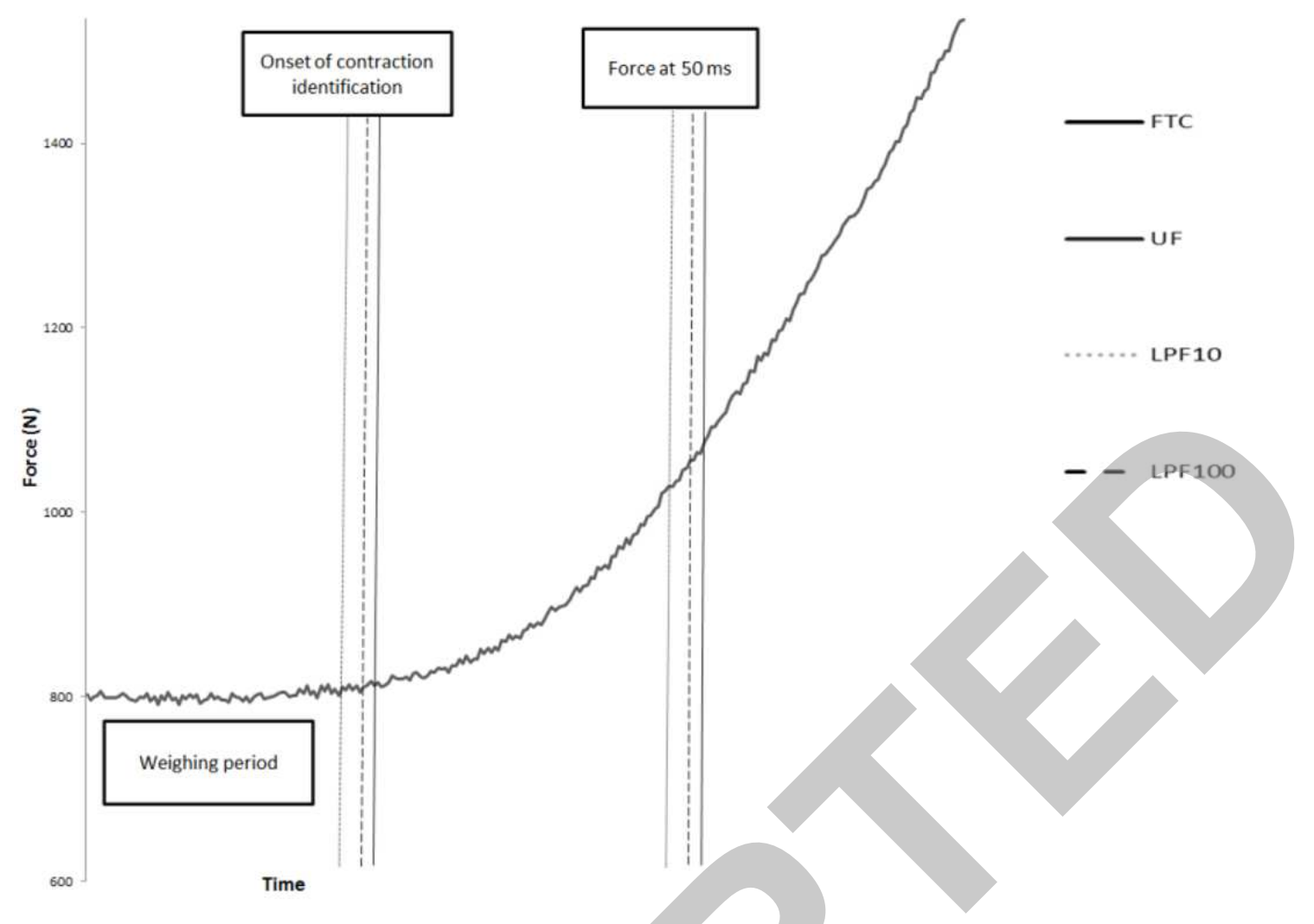

Figure 1. Example force-time curve illustrating the differences in onset of contraction and force at $50 \mathrm{~ms}$ identification between filtering conditions 